\title{
Age-Dependent Myocardial Dysfunction in Critically Ill Patients: Role of Mitochondrial Dysfunction
}

\author{
Andrew J. Lautz and Basilia Zingarelli * \\ Division of Critical Care Medicine, Cincinnati Children's Hospital Medical Center, and Department of Pediatrics, \\ College of Medicine, University of Cincinnati, Cincinnati, OH 45229, USA \\ * Correspondence: basilia.zingarelli@cchmc.org; Tel.: +1-513-636-8704; Fax: +1-513-636-4892
}

Received: 29 April 2019; Accepted: 16 July 2019; Published: 18 July 2019

\begin{abstract}
Myocardial dysfunction is common in septic shock and post-cardiac arrest but manifests differently in pediatric and adult patients. By conventional echocardiographic parameters, biventricular systolic dysfunction is more prevalent in children with septic shock, though strain imaging reveals that myocardial injury may be more common in adults than previously thought. In contrast, diastolic dysfunction in general and post-arrest myocardial systolic dysfunction appear to be more widespread in the adult population. A growing body of evidence suggests that mitochondrial dysfunction mediates myocardial depression in critical illness; alterations in mitochondrial electron transport system function, bioenergetic production, oxidative and nitrosative stress, uncoupling, mitochondrial permeability transition, fusion, fission, biogenesis, and autophagy all may play key pathophysiologic roles. In this review we summarize the epidemiologic and clinical phenotypes of myocardial dysfunction in septic shock and post-cardiac arrest and the multifaceted manifestations of mitochondrial injury in these disease processes. Since neonatal and pediatric-specific data for mitochondrial dysfunction remain sparse, conclusive age-dependent differences are not clear; instead, we highlight what evidence exists and identify gaps in knowledge to guide future research. Finally, since focal ischemic injury (with or without reperfusion) leading to myocardial infarction is predominantly an atherosclerotic disease of the elderly, this review focuses specifically on septic shock and global ischemia-reperfusion injury occurring after resuscitation from cardiac arrest.
\end{abstract}

Keywords: sepsis; cardiac arrest; age; echocardiography; mitochondria; energy metabolism

\section{Epidemiology of Sepsis and Cardiac Arrest}

Sepsis-3 defined sepsis as life-threatening organ dysfunction caused by a dysregulated host response to infection [1], and this pathophysiologic process represents the major cause of morbidity and mortality in children and adults [2-5]. The incidence of sepsis is disproportionately increased in elderly adults, and age is an independent predictor of mortality when compared with pediatric or young adult sepsis patients $[2,3,6]$. While mortality statistics are certainly different between the pediatric and the adult population, children and adult patients often experience cardiovascular dysfunction at a similar rate. In a large, multinational, point prevalence study of severe sepsis, $67 \%$ of critically ill children had multi-organ dysfunction at sepsis recognition and $70 \%$ had cardiovascular dysfunction in particular [7]. This data is confirmed by other pediatric studies, which suggest the majority of children with septic shock have evidence of myocardial dysfunction $[8,9]$. Septic myocardial dysfunction is similarly prevalent in adults, with estimates approaching $70 \%$ depending on the echocardiographic parameter examined [10-12].

Estimates for the incidence of cardiac arrest in the United States are also much higher in adults than in children. Cardiac arrest occurs in hospital in 6000 children each year in the United States [13,14] and out of hospital in another 5000 children [15]. In comparison, out-of-hospital cardiac arrest 
is estimated to occur in 300,000 adults annually in the United States, while 200,000 adults suffer in-hospital cardiac arrest [16]. There is limited pediatric evidence documenting the incidence of post-arrest myocardial dysfunction, but one study found left ventricular systolic dysfunction in $41 \%$ of children after out-of-hospital cardiac arrest [17]. Post-arrest myocardial dysfunction is more common in adults after resuscitation from cardiac arrest, impacting $72-75 \%$ of adults after out-of-hospital cardiac arrest in two studies $[18,19]$, though this may relate to the high prevalence of coronary artery disease in this population [20]. Post-cardiac arrest myocardial dysfunction is classically described as a transient phenomenon lasting 24-48 h [21], and recent studies of temporal changes in myocardial function after cardiac arrest support this notion $[22,23]$.

\section{Clinical Characteristics}

Infants and young children with septic shock often present with elevated systemic vascular resistance and low cardiac output in the context of myocardial dysfunction as part of a cold shock phenotype $[24,25]$. Biventricular dysfunction appears to be common. In a pediatric study in children with fluid- and catecholamine-refractory septic shock, $72 \%$ of patients had evidence of left ventricular (LV) dysfunction, while 63\% had some degree of right ventricular (RV) dysfunction [8]. Cardiovascular impairment in pediatric septic shock is not limited to systolic dysfunction; estimates for diastolic dysfunction range from $41-48 \%$ for the LV and approach $35 \%$ for the RV $[8,26]$. This cardiac dysfunction is also common in neonatal sepsis, as both LV and RV systolic and diastolic dysfunction can occur [27]. Importantly, distinguishing LV and RV impairment and identifying diastolic dysfunction may facilitate more accurate titration of hemodynamic support in children with septic shock $[26,28,29]$. It must be noted, though, that when speckle tracking echocardiography is employed in children with sepsis and septic shock, impaired ventricular performance is detected, even when the ejection fraction (EF) appears normal, and is associated with worsening of global longitudinal and circumferential strain [30,31]. Whether titrating bedside therapies to improve indices of myocardial strain is of clinical benefit in pediatric septic shock remains an area for future research.

In contrast, adult septic shock is typically characterized by a warm shock phenotype with normal or elevated cardiac output and low systemic vascular resistance [32]. However, EF is a load-dependent measurement and is a potentially misleading metric in states of altered afterload and preload. For example, in a recent study in adult patients with septic shock, Boissier et al. reported that $78 \%$ of patients had normal or elevated EF, which manifested with higher cardiac index and lower parameters of afterload, while only $22 \%$ of patients presented with low EF [10]. However, when these latter patients were monitored with the application of speckle tracking imaging, a much higher proportion of myocardial dysfunction $(>70 \%)$ with impairment in global longitudinal strain was observed (Table 1) [10]. 
Table 1. Characteristics of myocardial dysfunction in septic shock and post-cardiac arrest.

\begin{tabular}{ccc}
\hline Septic Shock & Pediatrics & Adult \\
\hline Myocardial Dysfunction & $3 / 4$ of patients & Low EF in $1 / 4$ to $1 / 3^{*}$ \\
\hline LV systolic & $2 / 3$ of patients & $32-55 \%$ of patients ${ }^{*}$ \\
\hline RV systolic & $41-48 \%$ for LV $~ 35 \%$ for RV & $66-84 \%$ of patients \\
\hline Diastolic & & \\
\hline Biomarkers & $\uparrow$ with LV dysfunction & $\uparrow$ with $\downarrow$ EF \\
\hline B-natriuretic peptide & $\uparrow$ with LV and RV & $\uparrow$ with LV dysfunction \\
\hline Cardiac troponins & Pysfunction in neonates & Adult \\
\hline Post-Cardiac Arrest & $41 \%$ (single study) & $>50 \%$ \\
\hline Myocardial Dysfunction & $18 \%$ (single study) & $>50 \%$ \\
\hline LV systolic & $\sim 2 / 3$ for LV and RV & Common \\
\hline RV systolic & & No clear association \\
\hline Diastolic & No clear association & Not necessarily indicative \\
\hline Biomarkers & $\uparrow$ with LV dysfunction & of conary occlusion \\
\hline B-natriuretic peptide & & \\
\hline Cardiac troponins & & \\
\hline
\end{tabular}

Definitions of abbreviations: $\mathrm{EF}=$ ejection fraction; $\mathrm{LV}=$ left ventricle; $\mathrm{RV}=$ right ventricle. ${ }^{*}$ Strain imaging suggests systolic dysfunction may be much more prevalent $(>70 \%)$.

As in pediatric septic shock, adult sepsis is characterized by biventricular dysfunction. The prevalence of RV dysfunction ranges from $32-55 \%$ and when present is associated with severity of illness and mortality [33-35]. Diastolic dysfunction seems to be more prevalent in the adult population, occurring in $66-84 \%$ of patients, which may be related to underlying ischemic heart disease, hypertension, and diabetes [12,36]. As previously noted, speckle tracking echocardiography has the potential to reveal myocardial dysfunction not identified by conventional parameters. For example, conventional echocardiography demonstrated LV dysfunction in 33\% and RV dysfunction in $32 \%$ septic patients, while speckle tracking found LV dysfunction in $69 \%$ and RV dysfunction in $72 \%$ septic patients [11]. A recent meta-analysis also reported that worse myocardial function as measured by worse global longitudinal strain was associated with higher mortality in patients, while such an association was not valid for LV EF [37]. Taken together, this data suggests that strain analysis by speckle tracking echocardiography may be an important measurement in identifying sepsis-associated myocardial dysfunction in all age groups. Future research should more fully elucidate whether myocardial strain is an appropriate clinical marker to guide treatment in septic shock.

As occurs in septic shock, myocardial dysfunction after resuscitation from cardiac arrest appears to be a global process. A review of echocardiograms of children admitted after out-of-hospital cardiac arrest reported that, in addition to LV systolic dysfunction, $18 \%$ of patients had evidence of abnormal RV systolic function, $42 \%$ had abnormal septal wall movement, and approximately $65 \%$ of patients exhibited diastolic dysfunction of both ventricles [17]. In a study of adult patients with cardiac arrest, RV systolic dysfunction post-arrest was as prevalent as LV dysfunction (59\% and 63\% patients) and was independently predictive of survival and neurologic outcome [38]. Additional adult data further validates the notion that diastolic dysfunction is common post-arrest and does improve over time in survivors (Table 1) [22]. As in septic shock, identification of LV and RV systolic and diastolic dysfunction after cardiac arrest may be useful in guiding management at the bedside [39]. At present, however, the role of strain echocardiography in delineating myocardial dysfunction and in influencing therapeutic strategies post-cardiac arrest remains unknown and is an important area for future research. 


\section{Biomarkers}

Several biomarkers have been examined for their utility in identifying myocardial dysfunction in critical illness and in prognosticating outcome. B-natriuretic peptide (BNP), a hormone secreted by the ventricles in response to wall stretch, and its prohormone have been studied in pediatric and adult septic shock. Domico et al. found that admission BNP was higher in a small cohort of children with septic shock than in controls and was higher in cold shock than in warm shock; BNP was inversely correlated with fractional shortening and directly correlated with severity of illness [40]. This is further corroborated by pediatric data showing correlations of BNP with LV systolic dysfunction and with severity of illness in septic shock [8]. Thus, BNP may aid in the identification of children with sepsis-associated myocardial dysfunction, though temporal relationships with treatment and clinical improvement remain undefined.

The utility of BNP in adult sepsis, on the other hand, appears to vary in relation to the clinical course of illness. When examined in the Emergency Department in patients with suspected sepsis, elevated BNP was associated with mortality but had limited diagnostic utility in predicting progression to shock [41]. When examined in adults with confirmed sepsis during hospitalization, BNP levels correlated with tissue hypoxia, higher vasoactive use, lower EF, and mortality [42,43]. Conversely, improvement in BNP portends the return of myocardial function and survival [42,44], suggesting a potential role for BNP in monitoring patient response to the treatment of septic shock.

The role of BNP after cardiac arrest is less clear; BNP does not seem to be associated with the presence of LV systolic dysfunction in children after cardiac arrest [17], though elevated admission BNP is associated with unfavorable outcomes in adults after out-of-hospital cardiac arrest [45]. Currently, BNP may be more helpful in the identification of myocardial dysfunction in children and adults with septic shock, rather than after resuscitation from cardiac arrest.

Cardiac troponin is essential for muscle contraction and ventricular function, binding intracellular calcium to regulate the interaction between myosin and actin. In particular, cardiac troponin subunits $\mathrm{T}$ and I have also been extensively studied as biomarkers of myocardial dysfunction in critical illness. Cardiac troponin-T correlates with LV and RV systolic dysfunction and with mortality in late-onset neonatal sepsis [27]. Troponin-T has also been associated with LV diastolic dysfunction, RV dilation, and LV global longitudinal strain in adult septic shock $[46,47]$. An estimated two-thirds of adults with septic shock who have elevated high-sensitivity troponin-I have myocardial dysfunction, and troponin-I correlates with mortality in these patients [44,48]. The utility of troponin measurement in pediatric septic shock is less clear, however; although elevated troponin- $T$ is common in children with septic shock who have myocardial dysfunction, this elevation does not appear to have a clear association with diastolic dysfunction on multivariable analysis [26]. Future research will have to determine whether troponin measurement has a role in the identification of myocardial dysfunction and in prognostication in children with septic shock. Unlike BNP, troponin is associated with LV systolic dysfunction in children resuscitated from cardiac arrest [17]. In adults with out-of-hospital cardiac arrest, both troponin- $\mathrm{T}$ and $-\mathrm{I}$ are elevated and are not necessarily indicative of antecedent coronary occlusion (Table 1) $[19,22]$. Clinicians should thus be cautious in interpreting cardiac troponin levels in older patients in whom myocardial infarction may have precipitated cardiac arrest.

A few other biomarkers have been evaluated in adults with severe sepsis and septic shock, though little evidence exists at present to support their use. Secretoneurin and chromogranin A, both produced in myocardial and neuroendocrine tissue, have been correlated with mortality in adult septic shock $[49,50]$. Neutrophil gelatinase-associated lipocalin, often associated with acute kidney injury, is also associated with low EF, vasoactive support, and mortality in adults with severe sepsis or septic shock [51]. It remains to be seen if monitoring of any of these biomarkers offers any marginal benefit above that of BNP and cardiac troponins in septic shock and after resuscitation from cardiac arrest. 


\section{Energy Failure and Mitochondrial Dysfunction}

Mitochondrial dysfunction has been proposed as an important cause of sepsis-related organ failure, and mitochondrial ultrastructural damage and diminished adenosine triphosphate (ATP) production have been demonstrated in cardiomyocytes during sepsis in experimental animals and humans (Figure 1) [52-56]. One of the major pathophysiological events occurring in sepsis is impairment of mitochondrial respiratory chain complex activity and bioenergetic production. For example, polymicrobial sepsis, induced by cecal ligation and puncture (CLP), in young adult mice results in diminished myocardial complex IV (CIV, cytochrome c oxidase) activity for up to $48 \mathrm{~h}$, accompanied by decreased expression of CIV subunits [54,55]. Restoration of CIV activity with exogenous administration of cytochrome c improves survival after CLP, suggesting a potential causative role for mitochondrial dysfunction in mortality in sepsis [55]. Sepsis in young adult mice also results in decreased complex I (CI)- and complex II (CII)-driven respiration and reduction in maximum oxidative phosphorylation (OXPHOS) [57]. Since antioxidant administration with melatonin rescued CI, CII, and maximum OXPHOS in this model, oxidative and nitrosative damage may play a role in mediating mitochondrial dysfunction [57]. Supporting this notion, cardiac-specific overexpression of thioredoxin, a thiol-based antioxidant, rescues myocardial CI dysfunction [58]. Porcine models of young adult sepsis have also revealed CII and CIV dysfunction $24 \mathrm{~h}$ after onset of sepsis, correlating with impairments in myocardial stroke volume [59]. The heterogeneity in the sites of electron transport system (ETS) inhibition may reflect differences in animal selection, models for sepsis induction, and timing of measurements, but the aggregate evidence suggests that impairment in mitochondrial respiration occurs commonly in the septic myocardium.

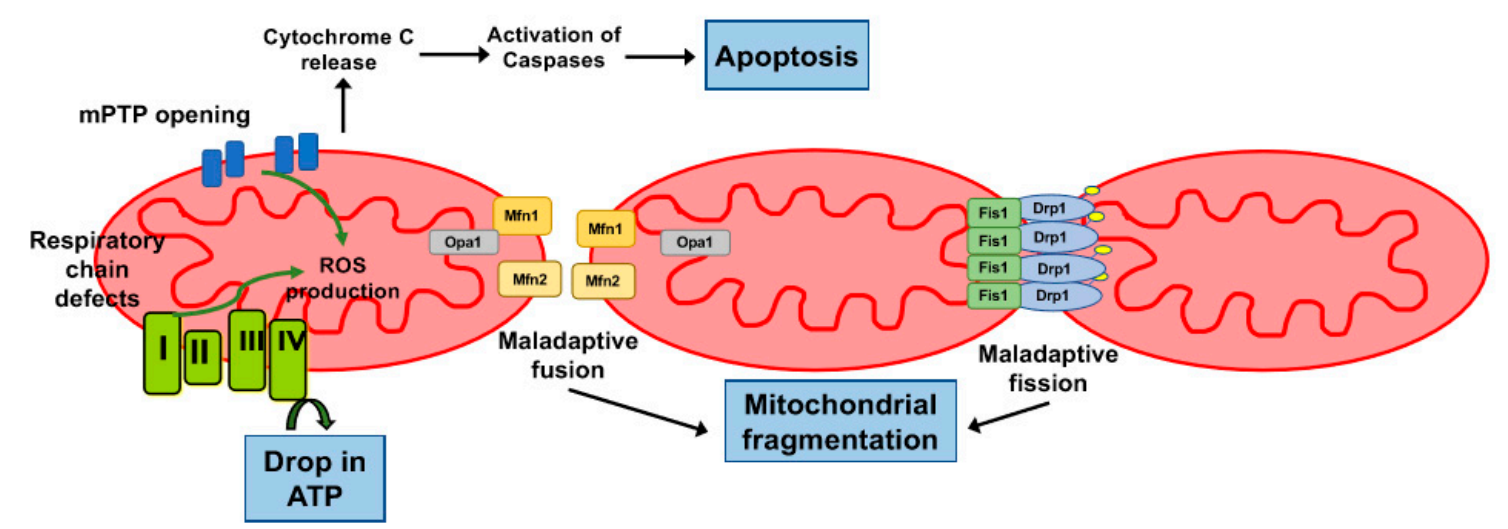

Figure 1. Mitochondrial dysfunction in cardiomyocytes in sepsis and cardiac arrest. Defects in activity of complexes I, II, and IV lead to a reduction of adenosine triphosphate (ATP) and an increase in reactive oxygen species (ROS). Other downstream consequences of mitochondrial permeability transition pore (mPTP) opening are cytochrome $\mathrm{C}$ release, increased caspase activity, and apoptosis. Opening of the MPTP contributes to energy failure. Defects in mitochondrial dynamics lead to mitochondrial fragmentation. Defects are related to increased expression of dynamin-related protein 1 (Drp1). Drp1 interacts with mitochondrial adaptor fission 1 (Fis1) on the outer mitochondrial membrane to facilitate mitochondrial fission. Inhibition of expression of mitofusin 1 (Mfn1) and mitofusin 2 (Mfn2), necessary for outer mitochondrial membrane fusion, as well as optic atrophy 1 (Opa1), which localizes to the inner mitochondrial membrane, leads to reduction of mitochondrial fusion.

The downstream effects of diminished mitochondrial respiration are alterations in myocardial bioenergetics. Endotoxin administration in adult rats leads to decreased myocardial ATP production and reduction in high-energy phosphate reserves in the form of creatine phosphate at early and late time points, in addition to myocardial dysfunction and inhibition of CI, CII, and CIV [60,61]. These changes are also accompanied by increased production of reactive oxygen species (ROS) and nitric oxide, further suggesting a possible link between CI dysfunction and nitrosative and oxidative 
injury [61]. Rats with polymicrobial sepsis exhibit a similar decline in myocardial ATP, creatinine phosphate, and glycogen stores [62], suggesting this phenotype is not unique to endotoxin models of sepsis. Since cardiac muscle contraction is an ATP-dependent process, these findings further add to the pathophysiologic link between mitochondrial dysfunction and sepsis-induced myocardial dysfunction.

However, it must be noted that all of these experimental studies have used models in young adult animals, and very few studies have directly compared multiple age groups. In a recent study from our laboratory, we have found that sepsis-induced myocardial dysfunction manifests with age-dependent characteristics, which are associated with a distinct metabolic dysregulation [63]. For example, middle-age mice (9-12 months old) exhibited more severe cardiac injury and worse mitochondrial derangement as compared to a younger group of mice (2-3 months old) despite equivalent troponin-I and -T levels after sepsis. Echocardiography revealed that young mice exhibited left ventricular systolic dysfunction, whereas middle-age mice exhibited reduction in stroke volume without apparent changes in load-dependent indices of cardiac function [63]. Other studies in six-week-old and twenty-month-old mice have demonstrated distinct age-dependent alterations in gene expression pathways related to amino acid and fatty acid metabolism, which can impact cellular bioenergetics after sepsis [64]. It is also known that reduced activity of the mitochondrial ETS and reduced cytochrome P450 expression in the myocardium also occur as part of normal aging [65], which may exacerbate the degree of mitochondrial dysfunction in septic shock. These unique transcriptional changes are also responsible for excessive ROS production by the mitochondria, thus becoming an important cause of enhanced susceptibility to myocardial dysfunction in adult and elderly patients [65,66].

Mitochondrial injury has also been clearly demonstrated in the myocardium after cardiac arrest. In a model of pediatric cardiac arrest using four-week-old piglets, CI dysfunction persisted in both the $\mathrm{LV}$ and $\mathrm{RV}$ in survivors at $24 \mathrm{~h}$, and the degree of $\mathrm{CI}$ dysfunction depended on the coronary perfusion pressure, a driver of coronary blood flow, during cardiopulmonary resuscitation [67], linking the extent of mitochondrial dysfunction with the severity of the ischemic injury to the myocardium. Similarly, young adult murine models of cardiac arrest have revealed early CI and CIV dysfunction in the context of ROS and reactive nitrogen species (RNS) generation [68,69]. Interestingly, in contrast to sepsis-induced myocardial dysfunction, CII dysfunction is not commonly reported after resuscitation from cardiac arrest; at present, it is unclear if and why sepsis may be more likely to induce CII dysfunction in the myocardium, in addition to CI and CIV dysfunction. As in septic shock, however, cardiac arrest also leads to diminished myocardial adenosine diphosphate (ADP) and ATP with increased intramyocellular lipid droplets and glycogen deposits suggestive of impaired substrate utilization [70]. While ETS dysfunction is evident in both juvenile and adult models of cardiac arrest, no studies as yet have directly compared mitochondrial function in survivors of cardiac arrest of different ages, and this remains an important area for future research.

As noted in the above discussion, oxidative and nitrosative damage may play a key pathophysiologic role in mitochondrial respiratory chain dysfunction in the heart in both septic shock and after cardiac arrest. ROS are generated at multiple sites in the mitochondria, including through electron leak at $\mathrm{CI}, \mathrm{CII}$, and complex III (CIII) to oxygen, creating superoxide radicals and hydrogen peroxide [71]. Impairment in respiratory chain function may encourage additional electron leak and ROS generation upstream in the ETS. Furthermore, reverse electron transport has been suggested as an important factor in ROS generation, with ischemic accumulation of succinate driving reverse electron transport from CII to CI at reperfusion [72]. This may be a particularly important mechanism in the myocardium after return of spontaneous circulation (ROSC) is achieved post-cardiac arrest, but whether this contributes to the pathophysiology of the septic heart remains poorly defined. Excessive ROS generation causes oxidative stress and impairs mitochondrial function, in part through oxidation of cardiolipin, an inner mitochondrial membrane phospholipid. This disrupts ETS complexes and may lead to the opening of mitochondrial permeability transition pores (discussed further below) [73]. Excess nitric oxide production also occurs in the myocardium in septic shock [74] and cardiac arrest [68], generating RNS such as peroxynitrite through interaction with superoxide radicals. This nitrosative stress also impairs 
mitochondrial ETS function, as peroxynitrite is a potent irreversible inhibitor of CI [75]. However, studies examining the influence of age on myocardial ROS and RNS generation in septic shock and post-cardiac arrest are lacking.

Finally, it should also be noted that mitochondrial uncoupling impacts ROS generation and may thereby influence oxidative damage in the septic myocardium and post-cardiac arrest. Mitochondrial ROS generation correlates with the proton-motive gradient; as respiration slows at higher proton-motive force, electron leak increases at CI, CII, and CIII [76]. Basal proton leak across the inner mitochondrial membrane dissipates this proton-motive force, and proton leak can be augmented by a family of inducible uncoupling proteins (UCP) [76,77]. Increased uncoupling, then, has the potential to limit ROS generation by the mitochondria, at the cost of diminishing ATP production. Whether UCP play a protective or pathophysiologic role in the heart post-cardiac arrest is largely unexplored, though there is emerging evidence that uncoupling protein 2 (UCP2) may be protective in the septic myocardium [78,79]. Once again, though, the extent and function of mitochondrial uncoupling in neonatal and pediatric myocardium in sepsis and cardiac arrest remains an area for future research.

\section{Role of the Mitochondrial Permeability Transition Pore}

The mitochondrial permeability transition pore (mPTP) is a heterogenous complex in the inner mitochondrial membrane whose composition has not yet been fully elucidated [80] but which is thought to contribute to myocardial dysfunction in septic shock and as part of ischemia-reperfusion injury occurring with resuscitation from cardiac arrest. While transient opening of the MPTP has been linked to physiologic ROS signaling and mitochondrial calcium efflux, prolonged opening of the MPTP leads to inner mitochondrial membrane depolarization, abolishing the proton-motive gradient necessary for ATP synthesis and thereby causing bioenergetic depletion of the cardiomyocyte [81,82]. Prolonged opening is also accompanied by mitochondrial swelling and rupture and release of pro-apoptotic factors such as cytochrome c, ultimately leading to apoptotic or necrotic cell death if mPTP opening extends to a significant portion of the cellular mitochondrial network [83,84] (Figure 1).

Notably, however, cardiomyocyte cell death is rarely observed in post mortem hearts from septic adults, despite the magnitude of organ dysfunction [56]. This suggests that widespread irreversible mPTP opening does not routinely occur in sepsis-associated myocardial dysfunction. Nevertheless, there is evidence implicating either 1) potentially reversible alterations in the $\mathrm{MPTP}$ or 2) irreversible mPTP opening in limited numbers of mitochondria in the pathogenesis of myocardial dysfunction in animal models of sepsis. Endotoxin-treated cardiomyocytes exhibit MPTP opening with mitochondrial membrane depolarization and ROS generation, which is ameliorated by treatment with cyclosporine A, an mPTP inhibitor [85]. Furthermore, inhibition of mPTP opening in both endotoxin and CLP models of adult sepsis improves OXPHOS, myocardial function, and survival [86-88]. These findings point to pathophysiologic changes in MPTP opening in the septic heart that fall short of catastrophic bioenergetic failure and initiation of cell death in most circumstances. It must be noted that all of these studies included only adult cardiomyocytes or adult animals; thus, the effects of mPTP opening on the juvenile myocardium in sepsis remains largely unexplored.

mPTP opening is similarly thought to be involved in myocardial dysfunction occurring after resuscitation from cardiac arrest. In fact, ROSC is associated with MPTP opening within minutes of reperfusion after the ischemic period. The $\mathrm{MPTP}$ is thought to remain closed during ischemia due to profound intracellular acidosis; with normalization of $\mathrm{pH}$ after reperfusion, the mPTP opens in response to intracellular calcium overload, ATP depletion, and oxidative stress [89,90]. This in turn arrests mitochondrial respiration by abrogating the proton gradient across the inner mitochondrial membrane, thereby stopping further ATP synthesis. Even so, as in septic shock, cardiomyocyte death is rare in survivors of cardiac arrest [91], arguing against widespread irreversible changes in the mPTP, which would be expected to activate cell death pathways. Lack of significant myocardial cell death in septic shock and post-cardiac arrest is also consistent with the known clinical course in survivors with recovery characterized by normalization of myocardial function. However, the degree of ischemia time 
prior to ROSC does seem to impact the degree of mPTP opening, with prolonged ischemic periods causing more changes in the MPTP [92]. Finally, the etiology of cardiac arrest may further impact the extent of mPTP opening, as asphyxial cardiac arrest appears to be associated with more extensive mPTP opening than does ventricular fibrillation cardiac arrest [69].

As in the septic myocardium, this transient or limited mPTP opening appears to play a pathophysiologic role in myocardial dysfunction post-cardiac arrest. After $15 \mathrm{~min}$ of untreated cardiac arrest in rabbits, administration of MPTP inhibitors improved myocardial function, lowered troponin leak, and improved maximum OXPHOS [89]. MPTP inhibition with cyclosporine has also been noted to improve both myocardial function and survival in adult rats, though administration must occur prior to ROSC to be efficacious, since reperfusion initiates MPTP opening [93]. While most studies have been performed in adult models of cardiac arrest, mPTP opening has been identified in the neonatal myocardium as well. It must be noted, however, that studies of neonatal cardiac arrest have focused on cardioplegic arrest in relation to cardiac surgery with cardiopulmonary bypass. Unlike in post-cardiac arrest myocardial dysfunction, apoptosis in the context of mPTP opening is much more common in the neonatal myocardium after cardioplegic arrest [94]. Inhibition of mPTP opening in neonatal cardioplegic arrest in rabbits with cyclosporine A improves myocardial function and CI respiration and reduces ROS production [94,95]. In a direct comparison of neonatal (6-8 days) and young adult (6-8 weeks) lambs who underwent cardioplegic arrest for cardiopulmonary bypass, neonatal myocardium exhibited more evidence of mPTP opening, characterized by increased cytochrome c release, caspase activity, and apoptosis [96]. At present, it is unclear whether this increased susceptibility to MPTP opening and apoptosis in the neonatal myocardium extends to cardiac arrest in general or if this remains limited to cardioplegic arrest for cardiac surgery. Further research is required to better delineate $\mathrm{mPTP}$ opening in the neonatal and pediatric myocardium in both septic shock and post-cardiac arrest. Cyclosporine A has recently been investigated as a therapeutic agent in adults post-cardiac arrest [97], but the multifaceted effects of calcineurin inhibitors such as cyclosporine complicate translation to human clinical trials.

As mPTP opening is triggered in the context of mitochondrial calcium overload, dysregulation in intracellular calcium can have potentially deleterious effects on the myocardium. At physiologic levels, calcium accelerates oxidative phosphorylation through stimulation of both Krebs cycle enzymes as well as complex V (ATP synthase) of the ETS [98]. Coupling of energy demand for calcium-dependent muscle contraction with energy production occurs in this way through close approximation of cardiac mitochondria with the sarcoplasmic reticulum, thought to be mediated by mitofusin-2 (discussed further below) [99]. An extensive discussion of intracellular calcium homeostasis is outside the scope of this review and is covered well elsewhere $[99,100]$, especially since few studies have examined mitochondrial calcium in the heart in septic shock and post-cardiac arrest and since neonatal and pediatric data are absent.

\section{Mitochondrial Dynamics in the Myocardium}

Emerging evidence suggests that disruption of normal mitochondrial fission and fusion, collectively termed mitochondrial dynamics and important for homeostasis of the intracellular mitochondrial network, contribute to organ failure in sepsis [101,102]. Mitochondrial fission mediates both mitochondrial replication and the sequestration of damaged parts of mitochondria by recruitment of dynamin-related protein 1 (Drp1) to the outer mitochondrial membrane [103]. Conversely, mitochondrial fusion is crucial for maintenance of the mitochondrial membrane potential and may rescue the function of damaged mitochondria. In addition to its role in tethering cardiac mitochondria to the sarcoplasmic reticulum, mitofusin 2 (Mfn2) and its counterpart mitofusin-1 (Mfn1) facilitate outer mitochondrial membrane fusion, while optic atrophy 1 (Opa1) protein is involved in fusion of the inner mitochondrial membrane (Figure 1) [103].

There are as yet no neonatal or pediatric-specific studies examining mitochondrial dynamics in the myocardium during sepsis, but data from adult models suggest the involvement of multiple 
signaling pathways and highlight the importance of the relative balance of fission and fusion [58]. Endotoxin administration in adult male mice results in increased Drp1 activation by phosphorylation (Ser616) in the myocardium, leading to mitochondrial fragmentation and decreases in CI, CII, and CIV-driven respiration and in left ventricular function [104]. Inhibition of the RhoA/ROCK (Ras-homologous A/RhoA-associated coiled-coil-containing protein kinases) pathway decreased Drp1 phosphorylation, normalizing mitochondrial length and improving respiration and myocardial function [104], while inhibition of the JNK-LATS2 (c-Jun N-terminal kinase/large tumor suppressor kinase 2) pathway reduced Drp1 expression and restored Opa1 and Mfn2 expression with improvement in myocardial function, ATP content, and mitochondrial size [105]. Similarly, Mst1 (Mammalian sterile 20-like kinase 1) activation seems to be involved in upregulation of Drp1 and suppression of Mfn1, Mfn2, and Opa1, leading to mitochondrial fragmentation in the myocardium after endotoxin exposure [106]. Finally, the interaction of Drp1 with mitochondrial adaptor fission 1 (Fis1) seems necessary for maladaptive fission in endotoxin models of sepsis, as inhibition of this interaction reduces mitochondrial fragmentation, myocardial dysfunction, and mortality [107]. The myriad pathways involved underscore the complexity of control over mitochondrial fission and fusion, but the aggregate evidence indicates a potentially pathologic role for mitochondrial fission in the adult septic heart.

Pathologic mitochondrial fission may also contribute to myocardial dysfunction after resuscitation from cardiac arrest in both neonates and adults. In neonatal murine cardiomyocytes, Drp1 inhibition preserved mitochondrial morphology and respiration after global ischemia-reperfusion injury; similarly, Drp1 inhibition prior to or following global ischemia-reperfusion in adult rat hearts reduced ROS generation and improved diastolic function [108]. Furthermore, Drp1 inhibition during cardiopulmonary resuscitation in a murine adult model of cardiac arrest normalized mitochondrial morphology in the myocardium, reduced time to ROSC, and improved post-resuscitation myocardial function and survival [109]. These promising data underscore the need for additional research to better delineate the role of mitochondrial dynamics in the myocardium both during sepsis and after resuscitation from cardiac arrest in all age groups and to outline the therapeutic potential of pharmacologic modulation of these processes.

In addition to mitochondrial fission and fusion, mitochondrial turnover is also mediated by autophagy and mitochondrial biogenesis. Autophagy mediates the removal of damaged organelles through lysosomal degradation [110], and mitophagy is the term applied to the targeted autophagy of damaged mitochondria before cell death pathways can be triggered by mitochondrial permeability transition [111]. In contrast, mitochondrial biogenesis, largely regulated by peroxisome proliferator-activated receptor (PPAR)- $\gamma$ coactivator-1 (PGC-1) $\alpha$ and $\beta$, refers to the generation of new mitochondria [112]. An extensive review of mitophagy and mitochondrial biogenesis is outside the scope of this review, but mitophagy may be crucial in cardiac recovery after resolution of sepsis [83], and biogenesis may be modulated in the septic myocardium [113]. Interestingly, these processes seem to be more robust in the neonate, as the resistance of neonatal cardiomyocytes to apoptosis has been attributed to both increased mitochondrial biogenesis and mitophagy [114]. Whether mitochondrial biogenesis and mitophagy play a larger role in neonatal and pediatric hearts in sepsis merits further exploration. Mitochondrial biogenesis and mitophagy are also being increasingly explored in post-cardiac arrest myocardial dysfunction $[115,116]$, but studies in younger patients are lacking.

\section{Conclusions}

Myocardial dysfunction consequent to sepsis or cardiac arrest is associated with profound changes in cardiac metabolism. Experimental data from animal models have revealed that mitochondrial dysfunction contributes to loss of cardiac metabolic flexibility and to contractile impairment. At present, however, most of the literature reports data from experimental models using young adult animals, which correspond in human age to adolescents or young adults and, therefore, poorly correlate with older adult or elderly sepsis. There is also a paucity of pre-clinical studies examining myocardial 
dysfunction and mitochondrial alterations in neonatal and pediatric age groups. Future research into myocardial dysfunction in sepsis and after cardiac arrest should employ models of multiple ages across the lifespan from early development to senescence to both further define age-specific differences in cardiac injury and to account for potential age-dependent responses to therapeutic interventions.

Funding: Supported by the National Institutes of Health grant K12 HD028827 to Andrew J. Lautz, and grants R01 GM-067202 and R01 GM-115973 to Basilia Zingarelli.

Conflicts of Interest: The authors declare no conflicts of interest.

\section{References}

1. Singer, M.; Deutschman, C.S.; Seymour, C.W.; Shankar-Hari, M.; Annane, D.; Bauer, M.; Bellomo, R.; Bernard, G.R.; Chiche, J.D.; Coopersmith, C.M.; et al. The Third International Consensus Definitions for Sepsis and Septic Shock (Sepsis-3). JAMA 2016, 315, 801-810. [CrossRef] [PubMed]

2. Watson, R.S.; Carcillo, J.A.; Linde-Zwirble, W.T.; Clermont, G.; Lidicker, J.; Angus, D.C. The epidemiology of severe sepsis in children in the United States. Am. J. Respir. Crit. Care Med. 2003, 167, 695-701. [CrossRef] [PubMed]

3. Angus, D.C.; Linde-Zwirble, W.T.; Lidicker, J.; Clermont, G.; Carcillo, J.; Pinsky, M.R. Epidemiology of severe sepsis in the United States: Analysis of incidence, outcome, and associated costs of care. Crit. Care Med. 2001, 29, 1303-1310. [CrossRef] [PubMed]

4. Ruth, A.; McCracken, C.E.; Fortenberry, J.D.; Hall, M.; Simon, H.K.; Hebbar, K.B. Pediatric severe sepsis: Current trends and outcomes from the Pediatric Health Information Systems database. Pediatr. Crit. Care Med. 2014, 15, 828-838. [CrossRef] [PubMed]

5. Balamuth, F.; Weiss, S.L.; Neuman, M.I.; Scott, H.; Brady, P.W.; Paul, R.; Farris, R.W.; McClead, R.; Hayes, K.; Gaieski, D.; et al. Pediatric severe sepsis in U.S. children's hospitals. Pediatr. Crit. Care Med. 2014, 15, 798-805. [CrossRef] [PubMed]

6. Martin, G.S.; Mannino, D.M.; Moss, M. The effect of age on the development and outcome of adult sepsis. Crit. Care Med. 2006, 34, 15-21. [CrossRef] [PubMed]

7. Weiss, S.L.; Fitzgerald, J.C.; Pappachan, J.; Wheeler, D.; Jaramillo-Bustamante, J.C.; Salloo, A.; Singhi, S.C.; Erickson, S.; Roy, J.A.; Bush, J.L.; et al. Global epidemiology of pediatric severe sepsis: The sepsis prevalence, outcomes, and therapies study. Am. J. Respir. Crit. Care Med. 2015, 191, 1147-1157. [CrossRef]

8. Williams, F.Z.; Sachdeva, R.; Travers, C.D.; Walson, K.H.; Hebbar, K.B. Characterization of Myocardial Dysfunction in Fluid- and Catecholamine-Refractory Pediatric Septic Shock and Its Clinical Significance. J. Intensive Care Med. 2016, 34, 17-25. [CrossRef]

9. Raj, S.; Killinger, J.S.; Gonzalez, J.A.; Lopez, L. Myocardial dysfunction in pediatric septic shock. J. Pediatr. 2014, 164, 2-77. [CrossRef]

10. Boissier, F.; Razazi, K.; Seemann, A.; Bedet, A.; Thille, A.W.; de Prost, N.; Lim, P.; Brun-Buisson, C.; Mekontso Dessap, A. Left ventricular systolic dysfunction during septic shock: The role of loading conditions. Intensive Care Med. 2017, 43, 633-642. [CrossRef]

11. Orde, S.R.; Pulido, J.N.; Masaki, M.; Gillespie, S.; Spoon, J.N.; Kane, G.C.; Oh, J.K. Outcome prediction in sepsis: Speckle tracking echocardiography based assessment of myocardial function. Crit. Care 2014, 18, R149. [CrossRef] [PubMed]

12. Rolando, G.; Espinoza, E.D.; Avid, E.; Welsh, S.; Pozo, J.D.; Vazquez, A.R.; Arzani, Y.; Masevicius, F.D.; Dubin, A. Prognostic value of ventricular diastolic dysfunction in patients with severe sepsis and septic shock. Rev. Bras. Ter. Intensiva 2015, 27, 333-339. [CrossRef] [PubMed]

13. Knudson, J.D.; Neish, S.R.; Cabrera, A.G.; Lowry, A.W.; Shamszad, P.; Morales, D.L.; Graves, D.E.; Williams, E.A.; Rossano, J.W. Prevalence and outcomes of pediatric in-hospital cardiopulmonary resuscitation in the United States: An analysis of the Kids' Inpatient Database. Crit. Care Med. 2012, 40, 2940-2944. [CrossRef] [PubMed]

14. Berg, R.A.; Sutton, R.M.; Holubkov, R.; Nicholson, C.E.; Dean, J.M.; Harrison, R.; Heidemann, S.; Meert, K.; Newth, C.; Moler, F.; et al. Ratio of PICU versus ward cardiopulmonary resuscitation events is increasing. Crit. Care Med. 2013, 41, 2292-2297. [CrossRef] [PubMed] 
15. Atkins, D.L.; Everson-Stewart, S.; Sears, G.K.; Daya, M.; Osmond, M.H.; Warden, C.R.; Berg, R.A. Resuscitation Outcomes Consortium, I., Epidemiology and outcomes from out-of-hospital cardiac arrest in children: The Resuscitation Outcomes Consortium Epistry-Cardiac Arrest. Circulation 2009, 119, 1484-1491. [CrossRef] [PubMed]

16. Mozaffarian, D.; Benjamin, E.J.; Go, A.S.; Arnett, D.K.; Blaha, M.J.; Cushman, M.; de Ferranti, S.; Despres, J.P.; Fullerton, H.J.; Howard, V.J.; et al. Heart disease and stroke statistics-2015 update: A report from the American Heart Association. Circulation 2015, 131, 29-322. [CrossRef] [PubMed]

17. Conlon, T.W.; Falkensammer, C.B.; Hammond, R.S.; Nadkarni, V.M.; Berg, R.A.; Topjian, A.A. Association of left ventricular systolic function and vasopressor support with survival following pediatric out-of-hospital cardiac arrest. Pediatr. Crit. Care Med. 2015, 16, 146-154. [CrossRef] [PubMed]

18. Bro-Jeppesen, J.; Annborn, M.; Hassager, C.; Wise, M.P.; Pelosi, P.; Nielsen, N.; Erlinge, D.; Wanscher, M.; Friberg, H.; Kjaergaard, J.; et al. Hemodynamics and vasopressor support during targeted temperature management at 33 degrees $C$ Versus 36 degrees $C$ after out-of-hospital cardiac arrest: A post hoc study of the target temperature management trial. Crit. Care Med. 2015, 43, 318-327. [CrossRef]

19. Dumas, F.; Manzo-Silberman, S.; Fichet, J.; Mami, Z.; Zuber, B.; Vivien, B.; Chenevier-Gobeaux, C.; Varenne, O.; Empana, J.P.; Pene, F.; et al. Can early cardiac troponin I measurement help to predict recent coronary occlusion in out-of-hospital cardiac arrest survivors? Crit. Care Med. 2012, 40, 1777-1784. [CrossRef]

20. Bergum, D.; Nordseth, T.; Mjolstad, O.C.; Skogvoll, E.; Haugen, B.O. Causes of in-hospital cardiac arrest-Incidences and rate of recognition. Resuscitation 2015, 87, 63-68. [CrossRef]

21. Neumar, R.W.; Nolan, J.P.; Adrie, C.; Aibiki, M.; Berg, R.A.; Bottiger, B.W.; Callaway, C.; Clark, R.S.; Geocadin, R.G.; Jauch, E.C.; et al. Post-cardiac arrest syndrome: Epidemiology, pathophysiology, treatment, and prognostication. A consensus statement from the International Liaison Committee on Resuscitation (American Heart Association, Australian and New Zealand Council on Resuscitation, European Resuscitation Council, Heart and Stroke Foundation of Canada, InterAmerican Heart Foundation, Resuscitation Council of Asia, and the Resuscitation Council of Southern Africa); the American Heart Association Emergency Cardiovascular Care Committee; the Council on Cardiovascular Surgery and Anesthesia; the Council on Cardiopulmonary, Perioperative, and Critical Care; the Council on Clinical Cardiology; and the Stroke Council. Circulation 2008, 118, 2452-2483. [PubMed]

22. Jentzer, J.C.; Anavekar, N.S.; Mankad, S.V.; White, R.D.; Kashani, K.B.; Barsness, G.W.; Rabinstein, A.A.; Pislaru, S.V. Changes in left ventricular systolic and diastolic function on serial echocardiography after out-of-hospital cardiac arrest. Resuscitation 2018, 126, 1-6. [CrossRef] [PubMed]

23. Cha, K.C.; Kim, H.I.; Kim, O.H.; Cha, Y.S.; Kim, H.; Lee, K.H.; Hwang, S.O. Echocardiographic patterns of postresuscitation myocardial dysfunction. Resuscitation 2018, 124, 90-95. [CrossRef] [PubMed]

24. Deep, A.; Goonasekera, C.D.; Wang, Y.; Brierley, J. Evolution of haemodynamics and outcome of fluid-refractory septic shock in children. Intensive Care Med. 2013, 39, 1602-1609. [CrossRef] [PubMed]

25. Abdalaziz, F.A.; Algebaly, H.A.F.; Ismail, R.I.; El-Sherbini, S.A.; Behairy, A. The use of bedside echocardiography for measuring cardiac index and systemic vascular resistance in pediatric patients with septic shock. Rev. Bras. Ter. Intensiva 2018, 30, 460-470. [CrossRef] [PubMed]

26. Sankar, J.; Das, R.R.; Jain, A.; Dewangan, S.; Khilnani, P.; Yadav, D.; Dubey, N. Prevalence and outcome of diastolic dysfunction in children with fluid refractory septic shock-A prospective observational study. Pediatr. Crit. Care Med. 2014, 15, 370-378. [CrossRef] [PubMed]

27. Abdel-Hady, H.E.; Matter, M.K.; El-Arman, M.M. Myocardial dysfunction in neonatal sepsis: A tissue Doppler imaging study. Pediatr. Crit. Care Med. 2012, 13, 318-323. [CrossRef]

28. Ranjit, S.; Aram, G.; Kissoon, N.; Ali, M.K.; Natraj, R.; Shresti, S.; Jayakumar, I.; Gandhi, D. Multimodal monitoring for hemodynamic categorization and management of pediatric septic shock: A pilot observational study. Pediatr. Crit. Care Med. 2014, 15, 17-26. [CrossRef]

29. Conlon, T.W.; Himebauch, A.S.; Fitzgerald, J.C.; Chen, A.E.; Dean, A.J.; Panebianco, N.; Darge, K.; Cohen, M.S.; Greeley, W.J.; Berg, R.A.; et al. Implementation of a pediatric critical care focused bedside ultrasound training program in a large academic PICU. Pediatr. Crit. Care Med. 2015, 16, 219-226. [CrossRef]

30. Basu, S.; Frank, L.H.; Fenton, K.E.; Sable, C.A.; Levy, R.J.; Berger, J.T. Two-dimensional speckle tracking imaging detects impaired myocardial performance in children with septic shock, not recognized by conventional echocardiography. Pediatr. Crit. Care Med. 2012, 13, 259-264. [CrossRef] 
31. Haileselassie, B.; Su, E.; Pozios, I.; Fiskum, T.; Thompson, R.; Abraham, T. Strain Echocardiography Parameters Correlate With Disease Severity in Children and Infants With Sepsis. Pediatr. Crit. Care Med. 2016, 17, 383-390. [CrossRef] [PubMed]

32. Parker, M.M.; Shelhamer, J.H.; Natanson, C.; Alling, D.W.; Parrillo, J.E. Serial cardiovascular variables in survivors and nonsurvivors of human septic shock: Heart rate as an early predictor of prognosis. Crit. Care Med. 1987, 15, 923-939. [CrossRef] [PubMed]

33. Furian, T.; Aguiar, C.; Prado, K.; Ribeiro, R.V.; Becker, L.; Martinelli, N.; Clausell, N.; Rohde, L.E.; Biolo, A. Ventricular dysfunction and dilation in severe sepsis and septic shock: Relation to endothelial function and mortality. J. Crit. Care 2012, 27, 319 e9-319 e15. [CrossRef] [PubMed]

34. Vallabhajosyula, S.; Kumar, M.; Pandompatam, G.; Sakhuja, A.; Kashyap, R.; Kashani, K.; Gajic, O.; Geske, J.B.; Jentzer, J.C. Prognostic impact of isolated right ventricular dysfunction in sepsis and septic shock: An 8-year historical cohort study. Ann. Intensive Care 2017, 7, 94. [CrossRef] [PubMed]

35. Harmankaya, A.; Akilli, H.; Gul, M.; Akilli, N.B.; Ergin, M.; Aribas, A.; Cander, B. Assessment of right ventricular functions in patients with sepsis, severe sepsis and septic shock and its prognostic importance: A tissue Doppler study. J. Crit. Care 2013, 28, 1111 e7-1111 e11. [CrossRef] [PubMed]

36. Lanspa, M.J.; Gutsche, A.R.; Wilson, E.L.; Olsen, T.D.; Hirshberg, E.L.; Knox, D.B.; Brown, S.M.; Grissom, C.K. Application of a simplified definition of diastolic function in severe sepsis and septic shock. Crit. Care 2016, 20, 243. [CrossRef] [PubMed]

37. Sanfilippo, F.; Corredor, C.; Fletcher, N.; Tritapepe, L.; Lorini, F.L.; Arcadipane, A.; Vieillard-Baron, A.; Cecconi, M. Left ventricular systolic function evaluated by strain echocardiography and relationship with mortality in patients with severe sepsis or septic shock: A systematic review and meta-analysis. Crit. Care 2018, 22, 183. [CrossRef]

38. Ramjee, V.; Grossestreuer, A.V.; Yao, Y.; Perman, S.M.; Leary, M.; Kirkpatrick, J.N.; Forfia, P.R.; Kolansky, D.M.; Abella, B.S.; Gaieski, D.F. Right ventricular dysfunction after resuscitation predicts poor outcomes in cardiac arrest patients independent of left ventricular function. Resuscitation 2015, 96, 186-191. [CrossRef]

39. Peberdy, M.A.; Callaway, C.W.; Neumar, R.W.; Geocadin, R.G.; Zimmerman, J.L.; Donnino, M.; Gabrielli, A.; Silvers, S.M.; Zaritsky, A.L.; Merchant, R.; et al. Part 9: Post-cardiac arrest care: 2010 American Heart Association Guidelines for Cardiopulmonary Resuscitation and Emergency Cardiovascular Care. Circulation 2010, 122 (Suppl. S36), 768-786. [CrossRef]

40. Domico, M.; Liao, P.; Anas, N.; Mink, R.B. Elevation of brain natriuretic peptide levels in children with septic shock. Pediatr. Crit. Care Med. 2008, 9, 478-483. [CrossRef]

41. Perman, S.M.; Chang, A.M.; Hollander, J.E.; Gaieski, D.F.; Trzeciak, S.; Birkhahn, R.; Otero, R.; Osborn, T.M.; Moretti, E.; Nguyen, H.B.; et al. Relationship between B-type natriuretic peptide and adverse outcome in patients with clinical evidence of sepsis presenting to the emergency department. Acad. Emerg. Med. 2011, 18, 219-222. [CrossRef] [PubMed]

42. Post, F.; Weilemann, L.S.; Messow, C.M.; Sinning, C.; Munzel, T. B-type natriuretic peptide as a marker for sepsis-induced myocardial depression in intensive care patients. Crit. Care Med. 2008, 36, 3030-3037. [CrossRef] [PubMed]

43. Rivers, E.P.; McCord, J.; Otero, R.; Jacobsen, G.; Loomba, M. Clinical utility of B-type natriuretic peptide in early severe sepsis and septic shock. J. Intensive Care Med. 2007, 22, 363-373. [CrossRef]

44. Klouche, K.; Pommet, S.; Amigues, L.; Bargnoux, A.S.; Dupuy, A.M.; Machado, S.; Serveaux-Delous, M.; Morena, M.; Jonquet, O.; Cristol, J.P. Plasma Brain Natriuretic Peptide and Troponin Levels in Severe Sepsis and Septic Shock. J. Intensive Care Med. 2013, 29, 229-237. [CrossRef] [PubMed]

45. Sodeck, G.H.; Domanovits, H.; Sterz, F.; Schillinger, M.; Losert, H.; Havel, C.; Kliegel, A.; Vlcek, M.; Frossard, M.; Laggner, A.N. Can brain natriuretic peptide predict outcome after cardiac arrest? An observational study. Resuscitation 2007, 74, 439-445. [CrossRef] [PubMed]

46. Landesberg, G.; Jaffe, A.S.; Gilon, D.; Levin, P.D.; Goodman, S.; Abu-Baih, A.; Beeri, R.; Weissman, C.; Sprung, C.L.; Landesberg, A. Troponin Elevation in Severe Sepsis and Septic Shock. Crit. Care Med. 2014, 42, 790-800. [CrossRef] [PubMed]

47. De Geer, L.; Engvall, J.; Oscarsson, A. Strain echocardiography in septic shock-A comparison with systolic and diastolic function parameters, cardiac biomarkers and outcome. Crit. Care 2015, 19, 122. [CrossRef]

48. Kim, J.S.; Kim, M.; Kim, Y.J.; Ryoo, S.M.; Sohn, C.H.; Ahn, S.; Kim, W.Y. Troponin Testing for Assessing Sepsis-Induced Myocardial Dysfunction in Patients with Septic Shock. J. Clin. Med. 2019, 8, 239. [CrossRef] 
49. Rosjo, H.; Masson, S.; Caironi, P.; Stridsberg, M.; Magnoli, M.; Christensen, G.; Moise, G.; Urbano, M.C.; Gattinoni, L.; Pesenti, A.; et al. Prognostic Value of Secretoneurin in Patients With Severe Sepsis and Septic Shock: Data From the Albumin Italian Outcome Sepsis Study. Crit. Care Med. 2018, 46, 404-410. [CrossRef]

50. Rosjo, H.; Nygard, S.; Kaukonen, K.M.; Karlsson, S.; Stridsberg, M.; Ruokonen, E.; Pettila, V.; Omland, T.; Group, F.S. Prognostic value of chromogranin A in severe sepsis: Data from the FINNSEPSIS study. Intensive Care Med. 2012, 38, 820-829. [CrossRef]

51. Wang, B.; Chen, G.; Li, J.; Zeng, Y.; Wu, Y.; Yan, X. Neutrophil gelatinase-associated lipocalin predicts myocardial dysfunction and mortality in severe sepsis and septic shock. Int. J. Cardiol. 2017, 227, 589-594. [CrossRef]

52. Crouser, E.D. Mitochondrial dysfunction in septic shock and multiple organ dysfunction syndrome. Mitochondrion 2004, 4, 729-741. [CrossRef] [PubMed]

53. Brealey, D.; Brand, M.; Hargreaves, I.; Heales, S.; Land, J.; Smolenski, R.; Davies, N.A.; Cooper, C.E.; Singer, M. Association between mitochondrial dysfunction and severity and outcome of septic shock. Lancet 2002, 360, 219-223. [CrossRef]

54. Levy, R.J.; Vijayasarathy, C.; Raj, N.R.; Avadhani, N.G.; Deutschman, C.S. Competitive and noncompetitive inhibition of myocardial cytochrome C oxidase in sepsis. Shock 2004, 21, 110-114. [CrossRef] [PubMed]

55. Piel, D.A.; Deutschman, C.S.; Levy, R.J. Exogenous cytochrome C restores myocardial cytochrome oxidase activity into the late phase of sepsis. Shock 2008, 29, 612-616. [CrossRef]

56. Takasu, O.; Gaut, J.P.; Watanabe, E.; To, K.; Fagley, R.E.; Sato, B.; Jarman, S.; Efimov, I.R.; Janks, D.L.; Srivastava, A.; et al. Mechanisms of cardiac and renal dysfunction in patients dying of sepsis. Am. J. Respir. Crit. Care Med. 2013, 187, 509-517. [CrossRef]

57. Doerrier, C.; Garcia, J.A.; Volt, H.; Diaz-Casado, M.E.; Luna-Sanchez, M.; Fernandez-Gil, B.; Escames, G.; Lopez, L.C.; Acuna-Castroviejo, D. Permeabilized myocardial fibers as model to detect mitochondrial dysfunction during sepsis and melatonin effects without disruption of mitochondrial network. Mitochondrion 2016, 27, 56-63. [CrossRef]

58. Sanchez-Villamil, J.P.; D'Annunzio, V.; Finocchietto, P.; Holod, S.; Rebagliati, I.; Perez, H.; Peralta, J.G.; Gelpi, R.J.; Poderoso, J.J.; Carreras, M.C. Cardiac-specific overexpression of thioredoxin 1 attenuates mitochondrial and myocardial dysfunction in septic mice. Int. J. Biochem. Cell Biol. 2016, 81, 323-334. [CrossRef]

59. Jarkovska, D.; Markova, M.; Horak, J.; Nalos, L.; Benes, J.; Al-Obeidallah, M.; Tuma, Z.; Sviglerova, J.; Kuncova, J.; Matejovic, M.; et al. Cellular Mechanisms of Myocardial Depression in Porcine Septic Shock. Front. Physiol. 2018, 9, 726. [CrossRef]

60. Tatsumi, T.; Akashi, K.; Keira, N.; Matoba, S.; Mano, A.; Shiraishi, J.; Yamanaka, S.; Kobara, M.; Hibino, N.; Hosokawa, S.; et al. Cytokine-induced nitric oxide inhibits mitochondrial energy production and induces myocardial dysfunction in endotoxin-treated rat hearts. J. Mol. Cell Cardiol. 2004, 37, 775-784. [CrossRef]

61. Vanasco, V.; Magnani, N.D.; Cimolai, M.C.; Valdez, L.B.; Evelson, P.; Boveris, A.; Alvarez, S. Endotoxemia impairs heart mitochondrial function by decreasing electron transfer, ATP synthesis and ATP content without affecting membrane potential. J. Bioenerg. Biomembr. 2012, 44, 243-252. [CrossRef] [PubMed]

62. Watts, J.A.; Kline, J.A.; Thornton, L.R.; Grattan, R.M.; Brar, S.S. Metabolic dysfunction and depletion of mitochondria in hearts of septic rats. J. Mol. Cell Cardiol. 2004, 36, 141-150. [CrossRef] [PubMed]

63. Inata, Y.; Piraino, G.; Hake, P.W.; O’Connor, M.; Lahni, P.; Wolfe, V.; Schulte, C.; Moore, V.; James, J.M.; Zingarelli, B. Age-Dependent Cardiac Function during Experimental Sepsis: Effect of Pharmacological Activation of AMP-Activated Protein Kinase by AICAR. Am. J. Physiol. Heart Circ. Physiol. 2018, 315, 826-837. [CrossRef] [PubMed]

64. Checchia, P.A.; Schierding, W.; Polpitiya, A.; Dixon, D.; Macmillan, S.; Muenzer, J.; Stromberg, P.; Coopersmith, C.M.; Buchman, T.G.; Cobb, J.P. Myocardial transcriptional profiles in a murine model of sepsis: Evidence for the importance of age. Pediatr. Crit. Care Med. 2008, 9, 530-535. [CrossRef] [PubMed]

65. Boheler, K.R.; Volkova, M.; Morrell, C.; Garg, R.; Zhu, Y.; Margulies, K.; Seymour, A.M.; Lakatta, E.G. Sex-and age-dependent human transcriptome variability: Implications for chronic heart failure. Proc. Natl. Acad. Sci. USA 2003, 100, 2754-2759. [CrossRef] [PubMed]

66. Beal, M.F. Oxidatively modified proteins in aging and disease. Free Radic. Biol. Med. 2002, 32, 797-803. [CrossRef] 
67. Lautz, A.J.; Morgan, R.W.; Karlsson, M.; Mavroudis, C.D.; Ko, T.S.; Licht, D.J.; Nadkarni, V.M.; Berg, R.A.; Sutton, R.M.; Kilbaugh, T.J. Hemodynamic-Directed Cardiopulmonary Resuscitation Improves Neurologic Outcomes and Mitochondrial Function in the Heart and Brain. Crit. Care Med. 2019, 47, e241-e249. [CrossRef] [PubMed]

68. Han, F.; Da, T.; Riobo, N.A.; Becker, L.B. Early mitochondrial dysfunction in electron transfer activity and reactive oxygen species generation after cardiac arrest. Crit. Care Med. 2008, 36, S447-S453. [CrossRef] [PubMed]

69. Tsai, M.S.; Huang, C.H.; Tsai, S.H.; Tsai, C.Y.; Chen, H.W.; Cheng, H.J.; Hsu, C.Y.; Wang, T.D.; Chang, W.T.; Chen, W.J. The difference in myocardial injuries and mitochondrial damages between asphyxial and ventricular fibrillation cardiac arrests. Am. J. Emerg. Med. 2012, 30, 1540-1548. [CrossRef] [PubMed]

70. Fang, X.; Huang, Z.; Zhu, J.; Jiang, L.; Li, H.; Fu, Y.; Sun, S.; Tang, W. Ultrastructural evidence of mitochondrial abnormalities in postresuscitation myocardial dysfunction. Resuscitation 2012, 83, 386-394. [CrossRef] [PubMed]

71. Brand, M.D. Mitochondrial generation of superoxide and hydrogen peroxide as the source of mitochondrial redox signaling. Free Radic. Biol. Med. 2016, 100, 14-31. [CrossRef]

72. Chouchani, E.T.; Pell, V.R.; Gaude, E.; Aksentijevic, D.; Sundier, S.Y.; Robb, E.L.; Logan, A.; Nadtochiy, S.M.; Ord, E.N.J.; Smith, A.C.; et al. Ischaemic accumulation of succinate controls reperfusion injury through mitochondrial ROS. Nature 2014, 515, 431-435. [CrossRef] [PubMed]

73. Paradies, G.; Paradies, V.; De Benedictis, V.; Ruggiero, F.M.; Petrosillo, G. Functional role of cardiolipin in mitochondrial bioenergetics. Biochim. Biophys. Acta 2014, 1837, 408-417. [CrossRef] [PubMed]

74. Rabuel, C.; Samuel, J.L.; Lortat-Jacob, B.; Marotte, F.; Lanone, S.; Keyser, C.; Lessana, A.; Payen, D.; Mebazaa, A. Activation of the ubiquitin proteolytic pathway in human septic heart and diaphragm. Cardiovasc. Pathol. 2010, 19, 158-164. [CrossRef] [PubMed]

75. Riobo, N.A.; Clementi, E.; Melani, M.; Boveris, A.; Cadenas, E.; Moncada, S.; Poderoso, J.J. Nitric oxide inhibits mitochondrial NADH:ubiquinone reductase activity through peroxynitrite formation. Biochem. J. 2001, 359, 139-145. [CrossRef] [PubMed]

76. Brand, M.D. Uncoupling to survive? The role of mitochondrial inefficiency in ageing. Exp. Gerontol. 2000, 35, 811-820. [CrossRef]

77. Jastroch, M.; Divakaruni, A.S.; Mookerjee, S.; Treberg, J.R.; Brand, M.D. Mitochondrial proton and electron leaks. Essays Biochem. 2010, 47, 53-67. [CrossRef] [PubMed]

78. Zheng, G.; Lyu, J.; Liu, S.; Huang, J.; Liu, C.; Xiang, D.; Xie, M.; Zeng, Q. Silencing of uncoupling protein 2 by small interfering RNA aggravates mitochondrial dysfunction in cardiomyocytes under septic conditions. Int. J. Mol. Med. 2015, 35, 1525-1536. [CrossRef]

79. Huang, J.; Peng, W.; Zheng, Y.; Hao, H.; Li, S.; Yao, Y.; Ding, Y.; Zhang, J.; Lyu, J.; Zeng, Q. Upregulation of UCP2 Expression Protects against LPS-Induced Oxidative Stress and Apoptosis in Cardiomyocytes. Oxid. Med. Cell Longev. 2019, 2019, 2758262. [CrossRef]

80. He, J.; Carroll, J.; Ding, S.; Fearnley, I.M.; Walker, J.E. Permeability transition in human mitochondria persists in the absence of peripheral stalk subunits of ATP synthase. Proc. Natl. Acad. Sci. USA 2017, 114, 9086-9091. [CrossRef]

81. Kwong, J.Q.; Molkentin, J.D. Physiological and pathological roles of the mitochondrial permeability transition pore in the heart. Cell Metab. 2015, 21, 206-214. [CrossRef] [PubMed]

82. Karch, J.; Molkentin, J.D. Regulated necrotic cell death: The passive aggressive side of Bax and Bak. Circ. Res. 2015, 116, 1800-1809. [CrossRef] [PubMed]

83. Piquereau, J.; Godin, R.; Deschenes, S.; Bessi, V.L.; Mofarrahi, M.; Hussain, S.N.; Burelle, Y. Protective role of PARK2/Parkin in sepsis-induced cardiac contractile and mitochondrial dysfunction. Autophagy 2013, 9 , 1837-1851. [CrossRef] [PubMed]

84. Bernardi, P.; Di Lisa, F. The mitochondrial permeability transition pore: Molecular nature and role as a target in cardioprotection. J. Mol. Cell Cardiol. 2015, 78, 100-106. [CrossRef] [PubMed]

85. Joseph, L.C.; Kokkinaki, D.; Valenti, M.C.; Kim, G.J.; Barca, E.; Tomar, D.; Hoffman, N.E.; Subramanyam, P.; Colecraft, H.M.; Hirano, M.; et al. Inhibition of NADPH oxidase 2 (NOX2) prevents sepsis-induced cardiomyopathy by improving calcium handling and mitochondrial function. JCI Insight 2017, 2, 94248. [CrossRef] 
86. Fauvel, H.; Marchetti, P.; Obert, G.; Joulain, O.; Chopin, C.; Formstecher, P.; Neviere, R. Protective effects of cyclosporin A from endotoxin-induced myocardial dysfunction and apoptosis in rats. Am. J. Respir. Crit. Care Med. 2002, 165, 449-455. [CrossRef] [PubMed]

87. Larche, J.; Lancel, S.; Hassoun, S.M.; Favory, R.; Decoster, B.; Marchetti, P.; Chopin, C.; Neviere, R. Inhibition of mitochondrial permeability transition prevents sepsis-induced myocardial dysfunction and mortality. J. Am. Coll. Cardiol. 2006, 48, 377-385. [CrossRef]

88. Joshi, M.S.; Julian, M.W.; Huff, J.E.; Bauer, J.A.; Xia, Y.; Crouser, E.D. Calcineurin regulates myocardial function during acute endotoxemia. Am. J. Respir. Crit. Care Med. 2006, 173, 999-1007. [CrossRef]

89. Cour, M.; Abrial, M.; Jahandiez, V.; Loufouat, J.; Belaidi, E.; Gharib, A.; Varennes, A.; Monneret, G.; Thibault, H.; Ovize, M.; et al. Ubiquitous protective effects of cyclosporine A in preventing cardiac arrest-induced multiple organ failure. J. Appl. Physiol. 2014, 117, 930-936. [CrossRef]

90. Ong, S.B.; Samangouei, P.; Kalkhoran, S.B.; Hausenloy, D.J. The mitochondrial permeability transition pore and its role in myocardial ischemia reperfusion injury. J. Mol. Cell Cardiol. 2015, 78, 23-34. [CrossRef]

91. Song, F.; Shan, Y.; Cappello, F.; Rappa, F.; Ristagno, G.; Yu, T.; Li Volti, G.; Sun, S.; Weil, M.H.; Tang, W. Apoptosis is not involved in the mechanism of myocardial dysfunction after resuscitation in a rat model of cardiac arrest and cardiopulmonary resuscitation. Crit. Care Med. 2010, 38, 1329-1334. [CrossRef] [PubMed]

92. Leistner, M.; Sommer, S.; Kanofsky, P.; Leyh, R.; Sommer, S.P. Ischemia time impacts on respiratory chain functions and $\mathrm{Ca}^{2+}$-handling of cardiac subsarcolemmal mitochondria subjected to ischemia reperfusion injury. J. Cardiothorac. Surg. 2019, 14, 92. [CrossRef] [PubMed]

93. Huang, C.H.; Tsai, M.S.; Hsu, C.Y.; Su, Y.J.; Wang, T.D.; Chang, W.T.; Chen, W.J. Post-cardiac arrest myocardial dysfunction is improved with cyclosporine treatment at onset of resuscitation but not in the reperfusion phase. Resuscitation 2011, 82, S41-S47. [CrossRef]

94. Oka, N.; Wang, L.; Mi, W.; Caldarone, C.A. Inhibition of mitochondrial remodeling by cyclosporine A preserves myocardial performance in a neonatal rabbit model of cardioplegic arrest. J. Thorac. Cardiovasc. Surg. 2008, 135, 585-593. [CrossRef] [PubMed]

95. Leung, C.H.; Wang, L.; Fu, Y.Y.; Yuen, W.; Caldarone, C.A. Transient mitochondrial permeability transition pore opening after neonatal cardioplegic arrest. J. Thorac. Cardiovasc. Surg. 2011, 141, 975-982. [CrossRef] [PubMed]

96. Karimi, M.; Wang, L.X.; Hammel, J.M.; Mascio, C.E.; Abdulhamid, M.; Barner, E.W.; Scholz, T.D.; Segar, J.L.; Li, W.G.; Niles, S.D.; et al. Neonatal vulnerability to ischemia and reperfusion: Cardioplegic arrest causes greater myocardial apoptosis in neonatal lambs than in mature lambs. J. Thorac. Cardiovasc. Surg. 2004, 127, 490-497. [CrossRef]

97. Argaud, L.; Cour, M.; Dubien, P.Y.; Giraud, F.; Jossan, C.; Riche, B.; Hernu, R.; Darmon, M.; Poncelin, Y.; Tchenio, X.; et al. Effect of Cyclosporine in Nonshockable Out-of-Hospital Cardiac Arrest: The CYRUS Randomized Clinical Trial. JAMA Cardiol. 2016, 1, 557-565. [CrossRef] [PubMed]

98. Glancy, B.; Balaban, R.S. Role of mitochondrial Ca2+ in the regulation of cellular energetics. Biochemistry 2012, 51, 2959-2973. [CrossRef]

99. Kohlhaas, M.; Maack, C. Calcium release microdomains and mitochondria. Cardiovasc. Res. 2013, 98, $259-268$. [CrossRef]

100. Brookes, P.S.; Yoon, Y.; Robotham, J.L.; Anders, M.W.; Sheu, S.S. Calcium, ATP, and ROS: A mitochondrial love-hate triangle. Am. J. Physiol. Cell Physiol. 2004, 287, C817-C833. [CrossRef]

101. Arulkumaran, N.; Deutschman, C.S.; Pinsky, M.R.; Zuckerbraun, B.; Schumacker, P.T.; Gomez, H.; Gomez, A.; Murray, P.; Kellum, J.A.; Workgroup, A.X. Mitochondrial Function in Sepsis. Shock 2016, 45, 271-281. [CrossRef] [PubMed]

102. Gonzalez, A.S.; Elguero, M.E.; Finocchietto, P.; Holod, S.; Romorini, L.; Miriuka, S.G.; Peralta, J.G.; Poderoso, J.J.; Carreras, M.C. Abnormal mitochondrial fusion-fission balance contributes to the progression of experimental sepsis. Free Radic. Res. 2014, 48, 769-783. [CrossRef] [PubMed]

103. Suarez-Rivero, J.M.; Villanueva-Paz, M.; de la Cruz-Ojeda, P.; de la Mata, M.; Cotan, D.; Oropesa-Avila, M.; de Lavera, I.; Alvarez-Cordoba, M.; Luzon-Hidalgo, R.; Sanchez-Alcazar, J.A. Mitochondrial Dynamics in Mitochondrial Diseases. Diseases 2016, 5, 1. [CrossRef] [PubMed]

104. Preau, S.; Delguste, F.; Yu, Y.; Remy-Jouet, I.; Richard, V.; Saulnier, F.; Boulanger, E.; Neviere, R. Endotoxemia Engages the RhoA Kinase Pathway to Impair Cardiac Function By Altering Cytoskeleton, Mitochondrial Fission, and Autophagy. Antioxid. Redox Signal. 2016, 24, 529-542. [CrossRef] [PubMed] 
105. Tan, Y.; Ouyang, H.; Xiao, X.; Zhong, J.; Dong, M. Irisin ameliorates septic cardiomyopathy via inhibiting DRP1-related mitochondrial fission and normalizing the JNK-LATS2 signaling pathway. Cell Stress Chaperones 2019, 24, 595-608. [CrossRef] [PubMed]

106. Shang, X.; Li, J.; Yu, R.; Zhu, P.; Zhang, Y.; Xu, J.; Chen, K.; Li, M. Sepsis-related myocardial injury is associated with Mst1 upregulation, mitochondrial dysfunction and the Drp1/F-actin signaling pathway. J. Mol. Histol. 2019, 50, 91-103. [CrossRef] [PubMed]

107. Haileselassie, B.; Mukherjee, R.; Joshi, A.U.; Napier, B.A.; Massis, L.M.; Ostberg, N.P.; Queliconi, B.B.; Monack, D.; Bernstein, D.; Mochly-Rosen, D. Drp1/Fis1 interaction mediates mitochondrial dysfunction in septic cardiomyopathy. J. Mol. Cell Cardiol. 2019, 130, 160-169. [CrossRef] [PubMed]

108. Sharp, W.W.; Fang, Y.H.; Han, M.; Zhang, H.J.; Hong, Z.; Banathy, A.; Morrow, E.; Ryan, J.J.; Archer, S.L. Dynamin-related protein 1 (Drp1)-mediated diastolic dysfunction in myocardial ischemia-reperfusion injury: Therapeutic benefits of Drp1 inhibition to reduce mitochondrial fission. FASEB J. 2014, 28, 316-326. [CrossRef]

109. Sharp, W.W.; Beiser, D.G.; Fang, Y.H.; Han, M.; Piao, L.; Varughese, J.; Archer, S.L. Inhibition of the mitochondrial fission protein dynamin-related protein 1 improves survival in a murine cardiac arrest model. Crit. Care Med. 2015, 43, e38-e47. [CrossRef]

110. Linton, P.J.; Gurney, M.; Sengstock, D.; Mentzer, R.M., Jr.; Gottlieb, R.A. This old heart: Cardiac aging and autophagy. J. Mol. Cell Cardiol. 2015, 83, 44-54. [CrossRef]

111. Gross, A.; Katz, S.G. Non-apoptotic functions of BCL-2 family proteins. Cell Death Differ. 2017, 24, 1348-1358. [CrossRef] [PubMed]

112. Dorn, G.W., II; Vega, R.B.; Kelly, D.P. Mitochondrial biogenesis and dynamics in the developing and diseased heart. Genes Dev 2015, 29, 1981-1991. [CrossRef] [PubMed]

113. Vanasco, V.; Saez, T.; Magnani, N.D.; Pereyra, L.; Marchini, T.; Corach, A.; Vaccaro, M.I.; Corach, D.; Evelson, P.; Alvarez, S. Cardiac mitochondrial biogenesis in endotoxemia is not accompanied by mitochondrial function recovery. Free Radic. Biol. Med. 2014, 77, 1-9. [CrossRef] [PubMed]

114. Hickson-Bick, D.L.; Jones, C.; Buja, L.M. Stimulation of mitochondrial biogenesis and autophagy by lipopolysaccharide in the neonatal rat cardiomyocyte protects against programmed cell death. J. Mol. Cell Cardiol. 2008, 44, 411-418. [CrossRef] [PubMed]

115. Zhou, H.; Zhu, P.; Wang, J.; Zhu, H.; Ren, J.; Chen, Y. Pathogenesis of cardiac ischemia reperfusion injury is associated with CK2alpha-disturbed mitochondrial homeostasis via suppression of FUNDC1-related mitophagy. Cell Death Differ. 2018, 25, 1080-1093. [CrossRef] [PubMed]

116. Chi, L.; Wang, N.; Yang, W.; Wang, Q.; Zhao, D.; Sun, T.; Li, W. Protection of Myocardial Ischemia-Reperfusion by Therapeutic Hypercapnia: A Mechanism Involving Improvements in Mitochondrial Biogenesis and Function. J. Cardiovasc. Transl. Res. 2019. [CrossRef] 